\title{
Pathophysiological Factors which Determine the Exercise Intolerance in Patients with Juvenile Dermatomyositis
}

\author{
Tim Takken*,1, Elisabeth F. Elst ${ }^{2}$ and Janjaap van der Net ${ }^{1}$ \\ ${ }^{1}$ Department of Pediatric Physical Therapy \& Exercise Physiology and ${ }^{2}$ Department of Pediatric Immunology, \\ Wilhelmina Children's Hospital, University Medical Center Utrecht, The Netherlands
}

\begin{abstract}
Juvenile Dermatomyositis (JDM) is one of the idiopathic inflammatory myopathies in childhood. In this disease the immune system targets the microvasculature of the skeletal muscle and skin, leading to myopathy and a typical skin rash. During episodes of active disease patients experience a significant reduction in exercise tolerance which is not only related to loss in muscle mass. In this chapter we propose a model consisting of 5 pathways that could explain the reduced exercise tolerance in children with JDM. The five pathways are 1) the increased concentration of intramuscular cytokines, 2) the systemic inflammation process 3) the inflammation of the capillaries in the muscle 4) the result of hypo-activity and 5) the effect of glucocorticoid treatment on body mass gain and protein breakdown.
\end{abstract}

Keywords: Exercise, training, physical activity, pathophysiology, dermatomyositis, exercise intolerance.

\section{INTRODUCTION}

Juvenile Dermatomyositis (JDM) forms together with Juvenile Polymyositis and Sporadic Inclusion Body Myositis the idiopathic inflammatory myopathies in childhood. Of these three not commonly found diseases, JDM is the most frequent observed disease, the latter two are very rare diseases in childhood.

In JDM, the immune system targets the microvasculature of the skeletal muscle and skin, leading to myopathy and a typical skin rash $[1,2]$. The pathophysiology of JDM is still unknown. In general the age of onset has two peaks, 91 between 11 and 14 years. In all age groups there is a female predominance [3]. Since the introduction of new therapies, the attention has shifted from mortality towards morbidity and functional ability.

Generally the symptoms of weakness, muscles tenderness and stiffness follow the skin manifestations [4].

The main pathological changes found in muscle biopsies are muscle fiber degeneration and necrosis with inflammatory infiltration in perivascular, perimysial and endomysial areas. Atrophied fibers, particularly in perifascicular areas, and fibers with an abnormal architecture may be found as well [5]. Since long the focus in clinical follow-up in JDM patients has been on muscle testing as muscle weakness was the most prominent clinical symptom $[1,6]$. However, not only muscle strength is affected, other physiological properties such as exercise capacity as well [7, 8]. Other studies revealed disturbances in muscle metabolism of myositis patients [9-11]. This places the exercise capacity of diseased muscle in the focus of interest of clinicians [7, 8, 12, 13]. As a consequence, more physiological instruments, originally designed for the use in

\footnotetext{
*Address correspondence to this author at the Department of Pediatric Physical Therapy \& Exercise Physiology, Wilhelmina Children's Hospital, University Medical Center Utrecht, Room KB2.056.0, PO Box 85090, NL 3508 AB Utrecht, The Netherlands; Tel: +3130 2504030; Fax: +31 30 2505333; E-mail: t.takken@wkz.azu.nl
}

a healthy population, are being applied in a clinical population. In JDM patients, aerobic exercise tests have been used in the management and evaluation of their health status $[7,8]$. These exercise tests were able to determine the aerobic exercise capacity (i.e. $\mathrm{VO}_{2 \text { peak }}$ ). Besides aerobic physical fitness, recent reports are suggesting the importance of anaerobic physical fitness (intensive exercise lasting $<2$ minutes). This is not surprising, since the daily childhood activities consists of short-term bursts of intensive activities [14].

In this review, we propose 5 major pathways that could explain the exercise intolerance in JDM patients.

\section{EXERCISE INTOLERANCE IN JDM: HOW BIG IS THE PROBLEM?}

Broadly speaking, two general exercise forms can be distinguished, namely short-term intensive bouts of exercise, the so called anaerobic exercise capacity and the long-term endurance type of activity: the aerobic exercise capacity. In the following paragraphs studies investigating exercise capacities in JDM patients will be reviewed.

\section{Anaerobic Exercise Capacity}

The Wingate Anaerobic exercise test (WAnT) is a 30second all out cycle ergometry test, in which one must cycle against a rapidly progressive resistance. The test is found reliable and valid against other anaerobic indices such as invasively determined (by muscle biopsy) muscle metabolites and energy rich phosphates and muscle fiber type composition [15]. The WAnT has been used in healthy children [16], in patients with neuromuscular diseases [17] and in juvenile idiopathic arthritis [18, 19] to determine anaerobic exercise capacity. Recently we described the feasibility of the WAnT in JDM and Juvenile Polymyositis patients and found a decrease in their short-term anaerobic exercise capacity of approximately 30 percent compared to healthy controls (See Fig. 2; [20]). Hilario et al., [21] found 


\section{Exercise Intolerance: Pathways}

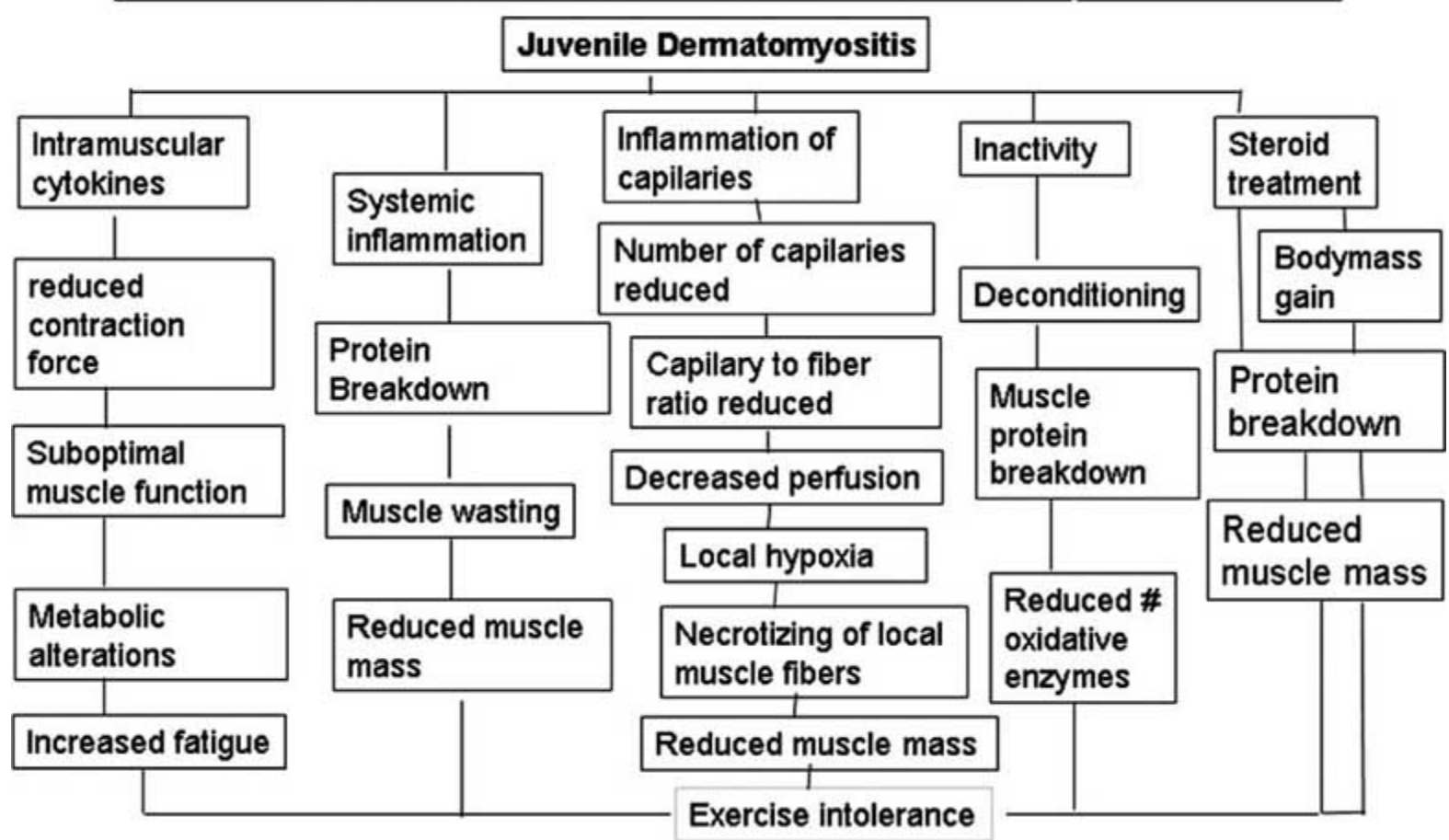

Fig. (1). Pathways leading to exercise intolerance in JIIM patients.

the greatest muscular atrophy in the gluteus maximus and the quadriceps muscle of patients with JDM, two muscles used in cycling exercise. In the light of these finding, the impaired anaerobic performance is not surprising. However, there was a broad scatter in performances in these patients ranging from -80 percent to scores above reference values for healthy children.

\section{Aerobic Exercise Capacity}

We recently tested the feasibility of maximum exercise testing in fifteen patients (age 5-14 years) with JDM, and

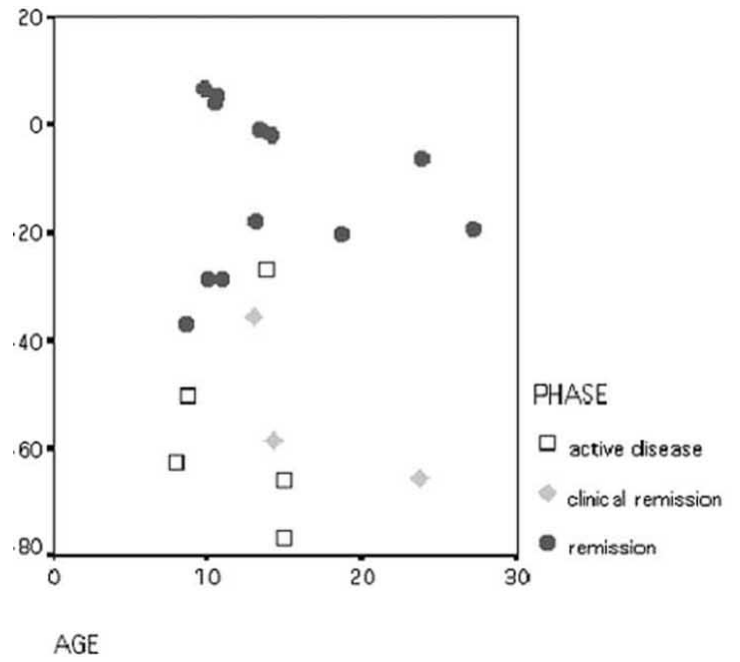

compared the obtained values with reference values for healthy children. Patients were tested using a motor driven treadmill and an apparatus for respiratory gas analysis, a so called metabolic cart, to volitional exhaustion conforming to the Bruce protocol [7].

In this study we found that all patients were able to perform the exercise test. Ten of the fifteen patients performed a maximal effort (heart rate $>180$ beats/min or respiratory exchange ratio $>1.0$ ). Five patients did not reach these criteria, since they experienced leg fatigue well before they were limited in their cardiovascular system.

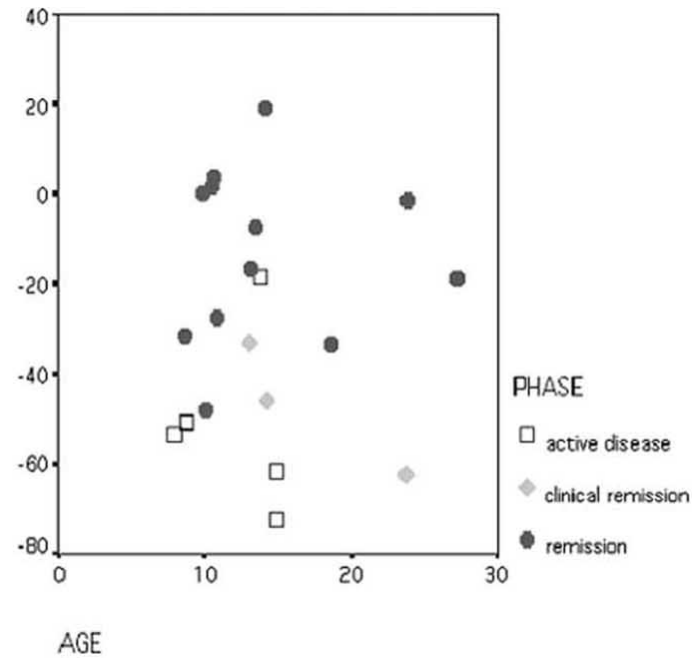

Fig. (2). Percentage impairment in anaerobic capacity of JIIM patients in relation to age and disease phase. Values are expressed as a percentage difference compared to healthy subjects. A positive value indicated a value above predicted, a negative value indicate a lower value compared to healthy controls. The left panel depicts the peak power, the right panel depicts the mean power. Data redrawn after Takken et al., [20]. 
For the patients who had a maximal exercise

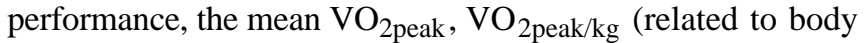
mass), and exercise time were respectively $-1.82( \pm 1.5)$, $-2.83( \pm 1.9)$, and $-3.65( \pm 1.9)$ standard deviations (SDscores) lower compared to age and sex matched reference values ( $\mathrm{p}<0.05)$ (Fig. 3). Expressed as percentage, patients with JDM had a $40 \%$ reduction in $\mathrm{VO}_{2 \text { peak }}$. The SD-scores for exercise time were significantly lower compared to SDscores for absolute and relative $\mathrm{VO}_{2 \text { peak }}$, an indication of reduced muscular economy. The differences between $\mathrm{VO}_{2 \text { peak }}$ and $\mathrm{VO}_{2 \text { peak/kg }}$ can be explained by a larger amount of non-metabolic active tissue (adipose tissue) in JDM patients (See also paragraph 5). These large reductions in exercise capacity have been confirmed by others in both adult dermato/polymyositis patients, as well as in patients with JDM. Wiesinger et al., tested 8 patients with dermatomyositis and 3 patients with polymyositis and found a reduction of $47 \%$ in $\mathrm{VO}_{2 \text { peak }}$ compared to healthy controls [12]. These data are comparable with the study of Hebert et al., [13] in 11 polymyositis/dermatomysitis patients. They found a $54 \%$ reduction in $\mathrm{VO}_{2 \text { peak }}$ in these patients compared to normal reference values. However, 3 of their patients performed the maximal exercise test within normal levels [13]. In children Hicks et al., [7] tested 14 children and adolescents with JDM using a maximal bicycle exercise test. In this study they found a $37 \%$ reduction in $\mathrm{VO}_{2 \text { peak }}$. Moreover, $\mathrm{VO}_{2 \text { peak }}$ correlated in this study significantly with disease damage indices such as physician global disease activity and damage and magnetic resonance imaging, suggesting the validity of the exercise testing measurements.

\section{Economy}

Park et al. [11] also suggest that JDM muscles have a lower economy (a larger energy cost per unit of work) when exercising at a sub-maximal exercise workload compared to healthy children. The discrepancy in Z-scores between the $\mathrm{VO}_{2 \text { peak }}$ (absolute and relative) and Z-scores for exercise time confirms this suggestion as running performance is influenced by muscular economy and $\mathrm{VO}_{2 \text { peak }}$ [22]. This was recently confirmed in the study by Drinkard et al. [23], who found a reduced delta oxygen uptake/work rate slope in JDM patients compared to healthy controls. Our own data confirm this observation, as can be appreciated from (Fig. 4). Normal values for the delta oxygen uptake/workrate relationship are 8.4 to $10.3 \mathrm{ml} / \mathrm{kg} / \mathrm{min}$ and might even be somewhat higher in elite athletes [24]. In this figure, 11 of 18 patients have a reduced delta oxygen uptake/work rate relationship. A reduced slope means that a larger part of the required energy production stems from anaerobic energy sources (anaerobic glycolysis). This is a disadvantage for the exercise capacity of the patient, since there are only limited stores of glucose and glycogen in the body. Moreover, the anaerobic glycolysis produces low amounts of energy from each glucose of glycogen molecule. Additionally, the anaerobic glycolysis forms metabolic waste products, such a lactic acid, which will increase lactate and $\mathrm{H}^{+}$concentrations in the blood what causes fatigue.

The lower muscular economy and oxidative capacity might be a result of dysfunctional muscle mitochondria with a low cytochrome C-oxidase activity [25] and/or a changed magnesium status in the muscle [10].

\section{Aerobic Exercise Capacity:JDM vs Controls}

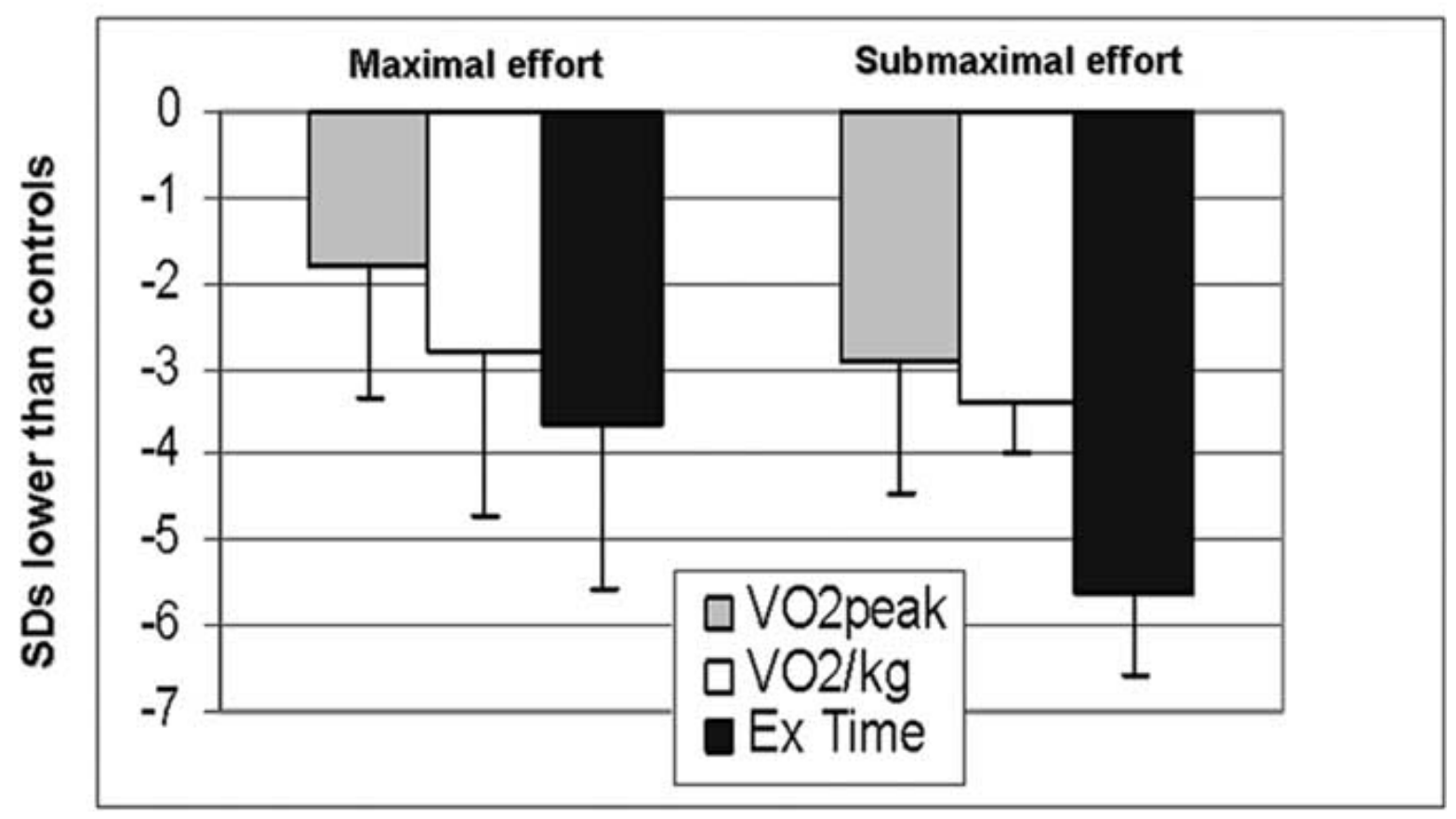

Fig. (3). The exercise capacity in JDM patients during maximal treadmill exercise. The shaded bars represent the absolute maximal oxygen uptake, the white bars represent the maximal oxygen uptake per kg body mass, the dark bars represent the exercise time. All values indicate SD-scores. Redrawn after data from reference [7]. 


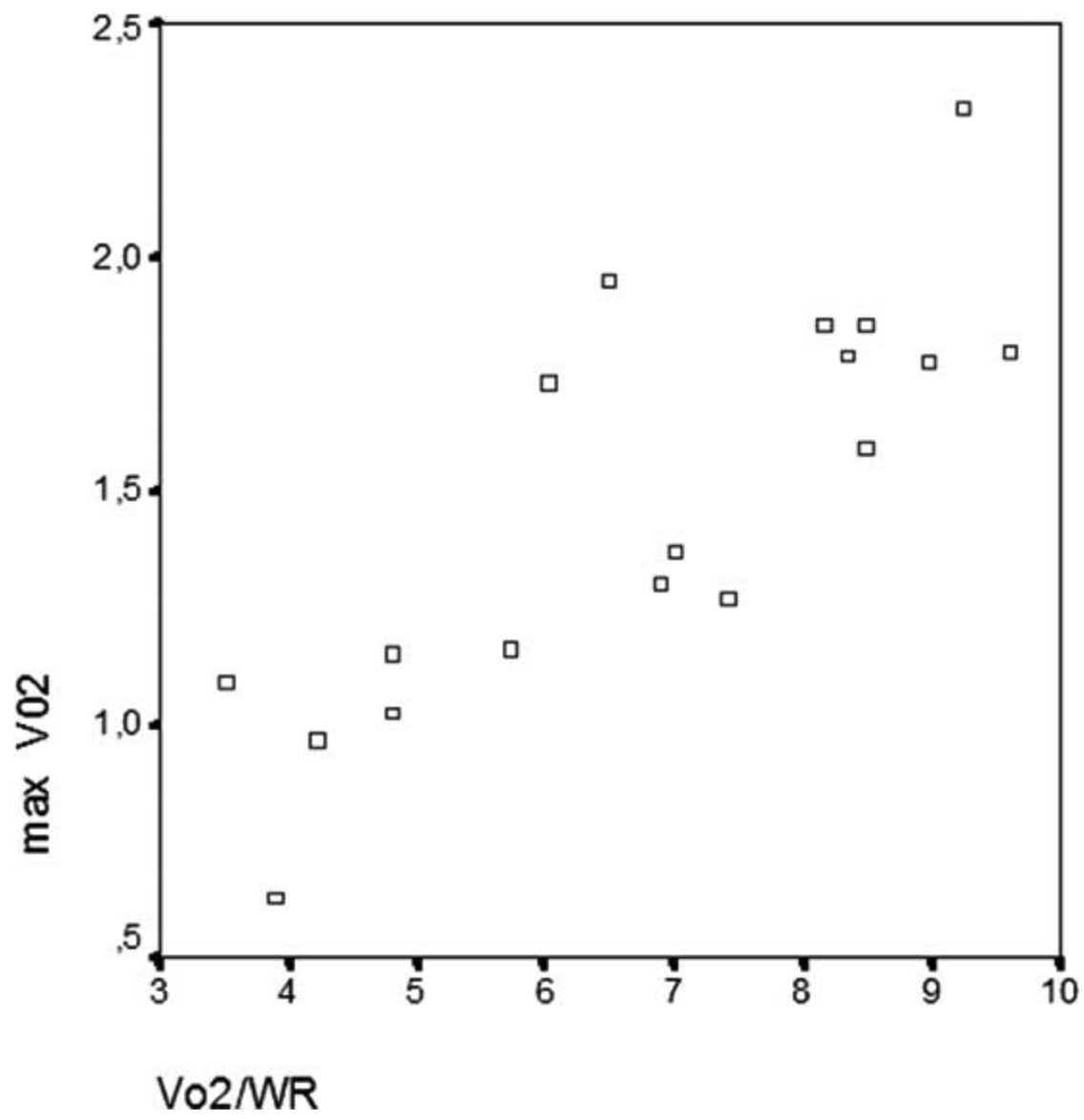

Fig. (4). Relationship between maximal oxygen uptake and efficiency. (Takken et al., unpublished observations).

In conclusion, patients with JDM have a significantly impaired exercise capacity compared to healthy controls. These values are associated with disease activity and damage in the muscle.

\section{INTRAMUSCULAR CYTOKINES}

An often observed phenomenon in inflammatory muscle diseases is that respiratory and skeletal muscles become weakened. During the early phase of the disease, muscle weakness may be severe without accompanying muscle atrophy, suggesting that other factors than loss of muscle mass are the cause of muscle weakness. Cytokines are likely to be potential mediators of this muscle weakness. Particularly tumor necrosis factor alpha (TNF $\alpha)$ could play a main role in this observation. $\mathrm{TNF} \alpha$ can stimulate muscle wasting (see paragraph 2) but can also induce contractile dysfunction without overt catabolism.

In a recent study, Reid et al. [26] studied this process in murine diaphragm and limb muscle and found that TNF $\alpha$ depressed tetanic force of the diaphragm and limb muscle to comparable degrees across a range of stimulus frequencies. Moreover, in isolated muscle fibers, TNF $\alpha$ decreased tetanic force without altering tetanic calcium transients or resting calcium levels. From these observations two conclusions can be drawn, firstly TNF $\alpha$ compromises contractile function of muscle similarly, and secondly $\mathrm{TNF} \alpha$ decreases force by blunting the response of muscle myofilaments to calcium activation.

One of the other described observations in inflammatory diseases is a reduced muscle protein synthesis. This process might be also related to the higher cytokine levels, with again an important role for TNF $\alpha$ [27]. The reduced myogenesis [28] results in a loss of muscle mass, since muscle breakdown is also increased under influence of again TNF $\alpha$, but also IL6 and IL-1 $\beta$ play a role in this process. This reduced muscle mass negatively influences muscle strength and exercise capacity [29].

\section{Altered Muscle Metabolism}

Patients with JIIM often experience strong exercise intolerance. Already in 1931 Steinitz \& Steinfeld reported abnormal muscle creatine levels and glucose metabolism in muscle of a patient with dermatomyositis [30]. Since then, several authors reported abnormal levels of energy rich phosphates (adenosine triphosphate; ATP, phosphocreatine; $\mathrm{PCr}$, inorganic phosphate; $\mathrm{Pi}$ ) and metabolites (e.g. Magnesium) in patients with JIIM and IIM. These findings have been reported in both rest and during exercise as measured using 31-P magnetic resonance imaging and spectroscopy (MRS) [9-11, 31]. Moreover, a defect in the purine-nucleotide cycle (adenosine monophosphate deaminase deficiency) in patients with IIM has been found [32]. 


\section{SYSTEMIC INFLAMMATION}

Idiopathic Inflammatory Myopathies are known to be associated with elevated serum concentrations of inflammatory cytokines (e.g. IL-1 $\beta, \mathrm{TNF} \alpha$ [1]. The crucial role of these cytokines in maintaining the balance between muscle protein synthesis and muscle protein degradation has been extensively studied in arthritic conditions by Roubenoff et al. [33]. This has lead to the notion of rheumatoid cachexia, a condition in which muscle protein degradation favors over muscle protein synthesis resulting in muscle wasting, impaired muscle strength and this is associated with increase of fat mass. The whole process is commonly referred to as 'cachexic obesity'. It is expected that a similar cascade of events might influence muscle protein metabolism in IIM, myopathic cachexia, enhancing the effect of loss of muscle strength by the inflammatory damage to the muscle by the disease itself. The disease is thought to induce muscle necrosis following circulatory insufficiency resulting from vasculitis, leading to muscle wasting and reduction in muscle strength. Moreover, the inflammatory cytokines that are produced in that condition of vasculitis, themselves influence muscle protein metabolism as well. However, in both conditions, Rheumatoid Arthritis and IIM, the precise mechanism is not yet elucidated. Roubenoff proposes a model based on his work in animal studies with arthritic conditions [34]. An adapted version of that model hypothesizes the situation in IIM conditions, this model will be outlined in (Fig. 5).
The model 'explains' the role of the inflammatory cytokines. IL-1 $\beta$ and TNF $\alpha$ acting synergistically to each other: A) a shift in protein metabolism towards a net catabolism is evident by raised resting energy expenditure, B) furthermore these cytokines mediate muscle degradation, and cause muscle necrosis. This leads to a loss of body cell mass predominantly skeletal muscle mass, and reduced physical activity, which reinforce each other and lead to further losses of skeletal muscle mass and predispose fat gain. Fat gain increases circulating TNF $\alpha$ levels (produced by adipocytes) and predisposes to insulin resistance and further muscle loss. This reinforces the negative cycle of muscle loss and fat gain, and causes myopathic obesity. These metabolic alterations cause muscle weakness that may contribute to physical disability, as well as co-morbidity.

Clinically it is evident that muscle weakness and increased obesity are factors that progressively influence exercise tolerance in a negative way. Limited exercise tolerance is positively associated with loss of activities of daily living and reduced activities in daily life. These factors both contribute negatively to health-related quality of life.

\section{INFLAMMATION OF CAPILLARIES}

The role of blood vessels in the pathogenesis of myositis was previously suggested based upon the decreased number of capillaries in the muscle tissue in recent-onset patients with dermatomyositis as well as the cytoplasmic inclusions in endothelial cells [35]. Moreover, these endothelial cells

\section{Inflammatory Myositis}

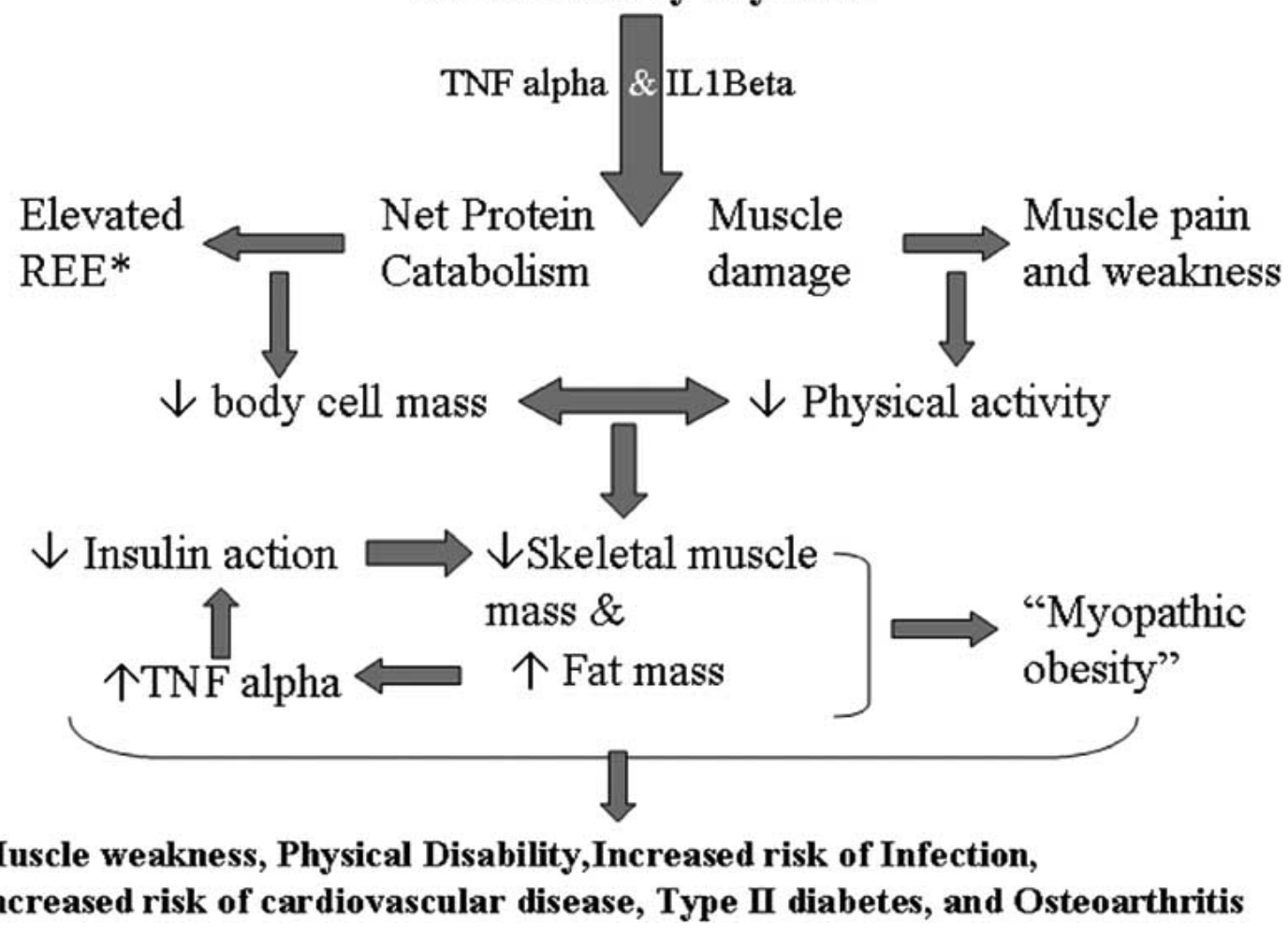

Fig. (5). Summary of the metabolic consequences of inflammatory myopathies. The increased levels of inflammatory parameters leads to a loss of body cell mass, predominantly skeletal muscle mass, and reduced physical activity, which reinforce each other and lead to further losses of skeletal muscle mass and predispose to fat gain. *Resting energy expenditure (REE) is elevated in active inflammatory diseases. Modified from Walsmith and Roubenoff [34]. 
appeared thickened, resembling the endothelial cells of high endothelium venules (HEV), which have a role in lymphocyte homing [36]. In the microvessels, arterioles and venules of patients with active myositis, there is an increased expression of certain proinflammatory cytokines such as Il-1 $\alpha$, adhesion molecules such as intercellular adhesion molecule 1 (ICAM-1) and vascular cell adhesion molecule 1 (VCAM-1) and class I major histocompatibility complex (MHC) [37]. Increased expression of these molecules was particularly evident in capillaries and small vessels in biopsy specimens from symptomatic muscles, both when these specimens contained inflammatory infiltrates and when such infiltrates where absent. This suggests that the decreased muscle function is more related to the expression of these molecules than to the mere presence of inflammatory cells in the affected muscles. This is an indication that the microvessels have a central role in the pathogenesis of inflammatory myositis.

Recent clinical research suggests that the abnormalities observed in some muscle biopsies are secondary to an impaired blood supply [38]. Hypoxia can upregulate both IL-1 and TGF- $\beta$, the cytokines most often detected in muscle tissues of patients with myositis [39, 40]. Hypoxia could be the result of a reduced number of capillaries reported in myositis biopsies, but it could also be generated in chronically inflamed tissue, as has been demonstrated in the synovial tissue of patients with rheumatoid arthritis [41].

The theory of an impaired blood supply is supported by the finding that in inflamed muscles hypoxia induces increased expression of angiogenic factors. Their impact however is insufficient to repair disease-associated reduction of the capillary network (34).

Several other studies have suggested that hypoxia of muscle fibres may have a role in the pathogenesis of JDM and therefore improving circulation to the muscles would be important. Circulation to the muscles is increased by exercise and therefore damage may be decreased if adequate blood and oxygen is supplied to the muscles. This may also have an impact upon the effects of TNF $\alpha$, which are primarily pro-inflammatory and $\mathrm{TNF} \alpha$ in increased amounts may increase the damage to muscles, but with improved circulation this effect may be reduced.

We found some excessive sweating in some of our JDM patients during exercise testing, although they were exercising at low workloads (Takken, unpublished observations). Recently it was found that the sweating response might be potentiated by muscle hypoxia [42].

\section{EFFECTS OF HYPOACTIVITY ON EXERCISE TOLERANCE}

There are several additional explanations for the decreased exercise tolerance of the patients with JDM. Sedentary subjects have fewer capillaries in their muscles per crosssectional area compared to subjects with an active life-style [43, 44]. Also, the activity of the oxidative enzymes is reduced and will result in a decreased capacity of the skeletal muscle to extract oxygen from the blood [45]. Moreover, disease or inactivity induced skeletal muscle atrophy reduces the total amount of oxygen which can be consumed by the muscles [46].
Bed rest will also impair exercise capacity. Already in 1968 Saltin et al., [44] described the detrimental effects of 3 weeks bedrest on exercise capacity in health young adults. In their widely cited Dallas Bedrest and Training Study, they described not only peripheral effects (in skeletal muscle) but also centrally (heart). The cardiac stroke volume during exercise was reduced after this period of bedrest. This lower stroke volume resulted in a reduced cardiac output. A recent follow-up of the original study participants, 30 years later showed that the reduction in exercise capacity after 3 weeks of bedrest was larger than the effects of 30 years of aging $[47,48]$ !

These inactivity-induced effects will lead to an impaired oxygen transport and extraction in the exercising muscle, higher mixed-venous oxygen content, and finally a reduced maximal oxygen uptake and exercise capacity.

\section{Training}

The reduced oxidative capacity of the muscles, which is probably caused by the low cytochrome oxydase levels, this is a key enzyme in the mitochondria of the skeletal muscles and regulates oxidative processes to produce ATP, might be improved by fitness training. A recent study showed that cytochrome oxydase levels could be improved in healthy adults using a fitness training program [49]. This indicates that fitness training might enhance the exercise capacity of JDM patients. Promising results have been found in physical training studies in adult dermatomyositis and polymyositis patients. Clinical trials from different laboratories have evaluated the effects of resistance training disease $[50,51]$ and endurance training $[52,53]$ in an adult dermato/polymyositis patients both with an active disease and in a clinically stable inactive condition. Arnadottir et al., $[54,55]$ found in a pilot study that a 12-week period of home training was safe for patients with inclusion body myositis (another form of inflammatory myositis).

One of these studies performed muscle biopsies before and after a training program and observed an increase in percentage of type I muscle fibers and an increase in crosssectional area of type II muscle fibers in polymyositis/dermatomyositis patients after a dynamic strength training program [56].

In children with IIM there is no exercise training program evaluated. However, Maillard found no increase in inflammation after performing moderate intensity exercises in JDM patients as evaluated using MRI derived T2 relaxation times $[55,57]$. This study in children also shows that a moderate exercise program is safe to perform in children with myositis and that exercise does not increase the levels of inflammation within the muscles.

Disease activity (inflammatory parameters) and medication (e.g. the effects of cyclosporin A (28) and prednisone (29)) could diminish the trainability of patients with JDM. However, it is known from the literature that steroid-induced muscular atrophy (See paragraph 5), can be reversed by physical training $[58,59]$. These findings need to be further investigated in the IIM/JDM patient population. 


\section{Nutritional Supplements}

In a supplementation study with a group of patients with various neuromuscular disorders including adult dermatomyositis and polymyositis patients, a significant improvement in muscle strength in these patients was observed [60]. It needs to be further investigated if supplementation of creatine monohydrate in patients with JIIM could reduce the impairment in anaerobic exercise capacity [61].

\section{STEROID TREATMENT}

\section{5a. General Considerations}

Glucocorticoids (GC) are among the most potent antiinflammatory agents that can be used in the treatment of rheumatic diseases. However, the short term benefits are frequently outweighed by the long term side effects, particularly in children [62].

GC alter the regulation of many cellular processes, including enzyme synthesis and activity, membrane permeability, transport processes, hormone and receptor synthesis and function and production of structural elements. They also have major effects on carbohydrate, protein and fat metabolism. The former participate primarily in the adaptive response to stress and inflammation, the latter are necessary for maintaining homeostasis. Unfortunately, the antiinflammatory effects of GC cannot be separated from the metabolic effects because all the cells of the body use the same glucocorticoid receptor (GCR).

The typical cushingoid appearance, with centripetal obesity, acne, hirsutism, moon facies, buffalo hump and striae of the skin may already occur with low doses of GC. Other side effects include growth suppression, osteoporosis, cataract, hypertension and psychologic disturbances.

Two distinct types of steroid myopathy have been described with systemic GC therapy. The chronic (or classic) form is usually an insidious disease process, which causes weakness mainly to the proximal muscles of the upper and lower limbs and neck flexors. There is a wide interpatient variability in the time course of symptom onset. Inactivity sensitizes skeletal muscle to the catabolic effects of steroids [63]. Another study with a rat model showed that steroid myopathy could be prevented by even mild exercise [64]. Isokinetic muscle testing of hip flexor strength appears to be the most sensitive and objective test of proximal muscle weakness. Levels of enzymes of muscle origin such as creatine phosphokinase (CPK) and aldolase almost never are elevated, except for elevated urinary creatine excretion. Biopsy of affected muscle reveals non-specific atrophy of the type IIb fast-twitch glycolytic fibers. There are many reports showing preventive effects of either growth hormone or insulin-like growth factor I on steroid myopathy [65]. In an experimental model, steroid therapy interfered with insulinlike growth factor I signaling, leading to increased myocyte apoptosis [66]. The acute form of steroid myopathy is less common, is associated with rhabdomyolysis and occurs abruptly while the patient is receiving high-dose corticosteroids. Affected patients often have markedly elevated levels of CPK and diffuse necrosis of skeletal muscle on biopsy specimens. In both forms, recovery begins after GC tapering or withdrawal, but more than 6 months may be required for complete resolution of muscle weakness.

\section{5b. Specific Effects on Energy Expenditure}

\section{Increased body mass}

A higher body mass is often the result of side effects of the GC resulting in a cushingoid appearance; this might account not only for the effects on psychosocial functioning, but an increased body mass (overweight) might restrict patients in the performance of activities of daily living.

Data from the literature show that energy expenditure is increased in obese patients during cycling, a non weight bearing activity [24]. During unloaded cycling as well as during loaded cycling, the oxygen uptake is higher in obese subjects. This is caused by the increased weight of the legs, which costs extra energy to raise the legs during cycling [24]. During weight bearing exercise this extra energy expenditure is even higher. The subject has to carry and extra load (body mass) and the leg swing of heavier legs might also increase the energy cost of locomotion [67].

\section{Decreased muscle mass}

Muscle atrophy is a common problem in this population group due to the catabolic effects of GC. Muscle atrophy implies a smaller muscle mass to consume oxygen during exercise. In addition, the metabolic function of muscle fibers can be altered. Impaired aerobic metabolism (due to decreased mitochondrial volume and/or mitochondrial myopathy) or reduced capillarisation can occur after immunosuppressive therapy [68]. Muscle atrophy and altered muscle function are further aggravated by sedentary habits due to the catabolic effects that sedentarism and prolonged bedrest induce on skeletal muscle tissue. As a result, muscle atrophy and early fatigue during low-to-moderate physical tasks become self-perpetuating conditions.

\section{CONCLUSION}

JDM is one of the inflammatory myopathies in childhood. Due to the disease process and consequences of the disease and treatment there are 5 pathways which contribute to the reduced exercise tolerance in these patients. The identification of these pathways makes them a possible target for intervention therapies. Possible therapies include anti-TNF $\alpha$ agents, Vascular Endothelial Growth Factor (VEGF) therapy, exercise and nutritional supplements. Exercise seems to have a possible important role in the treatment of JDM, since it might possibly upregulate VEGF expression and this enhancing angiogenesis in the muscle. Moreover, it reduced the inactivity related deconditioning and could prevent some of the deleterious effects of steroids (body mass gain and protein breakdown). However, no trials have been performed so far evaluating the effects of exercise in JDM patients. It is important to study the safety and effectiveness of exercise for treating JDM patients in a controlled trial before the shift from a bedrest-regime towards a more active treatment strategy can be made. 


\section{ACKNOWLEGDEMENTS}

The studies of Drs Takken and Van der Net are supported by a grant from the Dutch Arthritis Association. Dr Elst is supported by a grant from the Princess Beatrix Foundation.

\section{REFERENCES}

[1] Pachman LM. Juvenile dermatomyositis. Pathophysiology and disease expression. Pediatr Clin North Am 1995;42:1071-98.

[2] Wedderburn LR, Li CK. Paediatric idiopathic inflammatory muscle disease. Best Pract Res Clin Rheumatol 2004;18:345-58.

[3] Bowyer SL, Blane CE, Sullivan DB, Cassidy JT. Childhood dermatomyositis: factors predicting functional outcome and development of dystrophic calcification. J Pediatr 1983;103:882-8.

[4] Engel AG, Hohlfeld R, Banker BQ. Inflammatory myopathies. In: Basic and Clinical Myology. New-York: McGraw-Hill; 1994. p. 1335-1383.

[5] Jones DA, Round JM. Skeletal muscle in health and disease. A textbook of muscle physiology. Manchester: Manchester University Press; 1993.

[6] Resnick JS, Mammel M, Mundale MO, Kottke FJ. Muscular strength as an index of response to therapy in childhood dermatomyositis. Arch Phys Med Rehabil 1981;62:12-9.

[7] Takken T, Spermon N, Helders PJ, Prakken AB, Van Der Net J. Aerobic exercise capacity in patients with juvenile dermatomyositis. J Rheumatol 2003;30:1075-80.

[8] Hicks JE, Drinkard B, Summers RM, Rider LG. Decreased aerobic capacity in children with juvenile dermatomyositis. Arthritis Rheum 2002;47:118-23.

[9] Newman ED, Kurland RJ. P-31 magnetic resonance spectroscopy in polymyositis and dermatomyositis. Arthritis and Rheumatism 1992;35:199-203.

[10] Niermann KJ, Olsen NJ, Park JH. Magnesium abnormalities of skeletal muscle in dermatomyositis and juvenile dermatomyositis. Arthritis Rheum 2002;46:475-88.

[11] Park JH, Niermann KJ, Ryder NM, et al. Muscle abnormalities in juvenile dermatomyositis patients: P-31 magnetic resonance spectroscopy studies. Arthritis Rheum 2000;43:2359-67.

[12] Wiesinger GF, Quittan M, Nuhr M, et al. Aerobic capacity in adult dermatomyositis/polymyositis patients and healthy controls. Arch Phys Med Rehabil 2000;81:1-5.

[13] Hebert CA, Byrnes TJ, Baethge BA, Wolf RE, Kinasewitz GT. Exercise limitation in patients with polymyositis. Chest 1990;98:352-7.

[14] Bailey RC, Olson J, Pepper SL, Porszasz J, Barstow TJ, Cooper DM. The level and tempo of children's physical activities: an observational study. Med Sci Sports Exerc 1995;27:1033-41.

[15] Inbar O, Bar-Or O, Skinner JS. The wingate anaerobic test. Champaign, Ill.: Human Kinetics; 1996.

[16] Bar-Or O. The Wingate anaerobic test. An update on methodology, reliability and validity. Sports Med 1987;4:381-94

[17] Tirosh E, Bar-Or O, Rosenbaum P. New muscle power test in neuromuscular disease. Feasibility and reliability. Am J Dis Child 1990;144:1083-7.

[18] Takken T, Van der Net J, Helders PJ. Relationship between functional ability and physical fitness in juvenile idiopathic arthritis (JIA) patients. Scand J Rheumatol 2003;32:174-178.

[19] Malleson PN, Bennett SM, MacKinnon M, et al. Physical fitness and its relationship to other indices of health status in children with chronic arthritis. J Rheumatol 1996;23:1059-65.

[20] Takken T, van der Net J, Helders PJM. Anaerobic Exercise Capacity in Juvenile-onset Idiopathic Inflammatory Myositis (JIIM) Patients. Arthritis and Rheumatism Accepted for publication.

[21] Hilario MO, Yamashita H, Lutti D, Len C, Terreri MT, Lederman $H$. Juvenile idiopathic inflammatory myopathies: the value of magnetic resonance imaging in the detection of muscle involvement. Sao Paulo Med J 2000;118:35-40.

[22] Bassett DRJ, Howley ET. Limiting factors for maximum oxygen uptake and determinats of endurance performance. Medicine and Science in Sports and Exercise 2000;32:70-84.

[23] Drinkard BE, Hicks J, Danoff J, Rider LG. Fitness as a determinant of the oxygen uptake/work rate slope in healthy children and children with inflammatory myopathy. Can J Appl Physiol 2003;28:888-97.

[24] Wasserman K, Hansen JE, Sue DY, Casaburi R, Whipp BJ. Principles of Exercise testing and Interpretation. 3th Edition ed. Baltimore, MD, USA: Lippincott, Williams \& Wilkins; 1999.

[25] Woo M, Chung SJ, Nonaka I. Perifascicular atrophic fibers in childhood dermatomyositis with particular reference to mitochondrial changes. J Neurol Sci 1988;88:133-43.

[26] Reid MB, Lannergren J, Westerblad H. Respiratory and limb muscle weakness induced by tumor necrosis factor-alpha: involvement of muscle myofilaments. Am J Respir Crit Care Med 2002;166:479-84.

[27] Tisdale MJ. Cancer cachexia. Langenbecks Arch Surg 2004

[28] Langen RC, Schols AM, Kelders MC, Van Der Velden JL, Wouters EF, Janssen-Heininger YM. Tumor necrosis factor-alpha inhibits myogenesis through redox-dependent and -independent pathways. Am J Physiol Cell Physiol 2002;283:C714-21.

[29] Giordano A, Calvani M, Petillo O, Carteni M, Melone MR, Peluso G. Skeletal muscle metabolism in physiology and in cancer disease. J Cell Biochem 2003;90:170-86.

[30] Steinitz H, Steinfeld F. Untersuchungen zum Kreatinstoffwechsel bei Dermatomyositis. Zeitschrift fuer die Gesamte Experimentelle Medizin 1931;79:319-328.

[31] Pfleiderer B, Lange J, Loske K, Sunderkotter C. Metabolic disturbances during short exercises in dermatomyositis revealed by real-time functional $31 \mathrm{P}$ magnetic resonance spectrometry. Rheumatology 2004;43:696-703.

[32] Sabina RL, Sulaiman AR, Wortman RL. Molecular analysis of acquired myoadenulate deaminase deficiency in polymyositis (Idiopathic Inflammatory Myopathy). Advances In Experimental Medicine And Biology 1991;309b:203-205.

[33] Roubenoff R, Roubenoff RA, Cannon JG, et al. Rheumatoid cachexia: cytokine-driven hypermetabolism accompanying reduced body cell mass in chronic inflammation. J Clin Invest 1994;93:2379-86.

[34] Walsmith J, Roubenoff R. Cachexia in rheumatoid arthritis. Int J Cardiol 2002;85:89-99.

[35] Kissel JT, Mendell JR, Rammohan KW. Microvascular deposition of complement membrane attack complex in dermatomyositis. $\mathrm{N}$ Engl J Med 1986;314:329-34.

[36] Girard JP, Springer TA. High endothelial venules (HEVs): specialized endothelium for lymphocyte migration. Immunol Today 1995; 16:449-57.

[37] Englund P, Nennesmo I, Klareskog L, Lundberg IE. Interleukin1alpha expression in capillaries and major histocompatibility complex class I expression in type II muscle fibers from polymyositis and dermatomyositis patients: important pathogenic features independent of inflammatory cell clusters in muscle tissue. Arthritis Rheum 2002;46:1044-55.

[38] Cea G, Bendahan D, Manners D, et al. Reduced oxidative phosphorylation and proton efflux suggest reduced capillary blood supply in skeletal muscle of patients with dermatomyositis and polymyositis: a quantitative (31)P-magnetic resonance spectroscopy and MRI study. Brain 2002;125:1635-1645.

[39] Falanga V, Qian SW, Danielpour D, Katz MH, Roberts AB, Sporn MB. Hypoxia upregulates the synthesis of TGF-beta 1 by human dermal fibroblasts. J Invest Dermatol 1991;97:634-7.

[40] Shreeniwas R, Koga S, Karakurum M, et al. Hypoxia-mediated induction of endothelial cell interleukin-1 alpha. An autocrine mechanism promoting expression of leukocyte adhesion molecules on the vessel surface. J Clin Invest 1992;90:2333-9.

[41] Paleolog EM. Angiogenesis in rheumatoid arthritis. Arthritis Res 2002;4 Suppl 3:S81-90.

[42] Eiken O, Mekjavic IB. Ischaemia in working muscles potentiates the exercise-induced sweating response in man. Acta Physiol Scand 2004; 181:305-11.

[43] Wagner PD. An integrated view of the determinants of maximum oxygen uptake. Advances In Experimental Medicine And Biology 1988;227:245-56.

[44] Saltin B, Blomqvist G, Mitchell JH, Johnson RL, Jr., Wildenthal K, Chapman CB. Response to exercise after bed rest and after training. Circulation 1968;38:VII1-78.

[45] Holloszy JO, Coyle EF. Adaptations of skeletal muscle to endurance exercise and their metabolic consequences. J Appl Physiol 1984;56:831-8.

[46] Bar-Or O. Pathophysiological factors which limit the exercise capacity of the sick child. Med Sci Sports Exerc 1986;18:276-82. 
[47] McGuire DK, Levine BD, Williamson JW, et al. A 30-year follow-up of the Dallas Bedrest and Training Study: II. Effect of age on cardiovascular adaptation to exercise training. Circulation 2001;104:1358-66.

[48] McGuire DK, Levine BD, Williamson JW, et al. A 30-year follow-up of the Dallas Bedrest and Training Study: I. Effect of age on the cardiovascular response to exercise. Circulation 2001;104:1350-7.

[49] Carter SL, Rennie CD, Hamilton SJ, Tarnopolsky MA. Changes in skeletal muscle in males and females following endurance training. Can J Physiol Pharmacol 2001;79:386-92.

[50] Alexanderson $\mathrm{H}$, Stenstrom $\mathrm{CH}$, Jenner G, Lundberg I. The safety of a resistive home exercise program in patients with recent onset active polymyositis or dermatomyositis. Scand J Rheumatol 2000;29:295-301.

[51] Alexanderson H, Stenstrom CH, Lundberg I. Safety of a home exercise programme in patients with polymyositis and dermatomyositis: a pilot study. Rheumatology (Oxford) 1999;38:608-11.

[52] Wiesinger GF, Quittan M, Aringer M, et al. Improvement of physical fitness and muscle strength in polymyositis/dermatomyositis patients by a training programme. $\mathrm{Br}$ J Rheumatol 1998;37:196-200.

[53] Wiesinger GF, Quittan M, Graninger M, et al. Benefit of 6 months long-term physical training in polymyositis/dermatomyositis patients. Br J Rheumatol 1998;37:1338-42.

[54] Arnardottir S, Alexanderson H, Lundberg IE, Borg K. Sporadic inclusion body myositis: pilot study on the effects of a home exercise program on muscle function, histopathology and inflammatory reaction. J Rehabil Med 2002;35:31-35.

[55] Maillard S. Quantitative Assessment of the Effects of Exercise on Muscles in Children with Dermatomyositis [MSC]. London: City University; 2002.

[56] Esbjornsson-Liljedahl M, Dasmalchi M, Alexanderson $\mathrm{H}$, Stahlberg M, Lundberg IE. Changed muscle morphology in myositis patients following a home exercise program. In: Klarlund Petersen B, Febbraio M, Fleshner M, editors. 6th International
Society of Exercise Immunology Symposium; 2003; Copenhagen, Danmark; 2003. p. 47.

[57] Maillard SM, Jones R, Owens C, et al. Quantitative assessment of MRI T2 relaxation time of thigh muscles in juvenile dermatomyositis. Rheumatology (Oxford) 2004;43:603-8.

[58] Horber FF, Scheidegger JR, Grunig BE, Frey FJ. Evidence that prednisone-induced myopathy is reversed by physical training. J Clin Endocrinol Metab 1985;61:83-8.

[59] Hickson RC, Marone JR. Exercise and inhibition of glucocorticoid-induced muscle atrophy. Exerc Sport Sci Rev 1993;21:135-67.

[60] Tarnopolsky MA, Martin J. Creatine monohydrate increases strength in patients with neuromuscular disease. Neurology 1999;52:854-857.

[61] Tarnopolsky MA, Beal MF. Potential for creatine and other therapies targetting cellular energy dysfunction in neurological disorders. Ann Neurol 2001;49:561-574.

[62] Spahn JD, Kamada AK. Special considerations in the use of glucocorticoids in children. Pediatr Rev 1995;16:266-72.

[63] Ferrando AA, Stuart CA, Sheffield-Moore M, Wolfe RR. Inactivity amplifies the catabolic response of skeletal muscle to cortisol. J Clin Endocrinol Metab 1999;84:3515-21.

[64] Nakago K, Senda M, Touno M, Takahara Y, Inoue H. Influence of exercise on muscle fibers in rats with steroid myopathy. Acta Med Okayama 1999;53:265-70.

[65] Kanda F, Okuda S, Matsushita T, Takatani K, Kimura KI, Chihara K. Steroid myopathy: pathogenesis and effects of growth hormone and insulin-like growth factor-I administration. Horm Res 2001;56 Suppl 1:24-8.

[66] Singleton JR, Baker BL, Thorburn A. Dexamethasone inhibits insulin-like growth factor signaling and potentiates myoblast apoptosis. Endocrinology 2000;141:2945-50.

[67] Volpe Ayub B, Bar-Or O. Energy cost of walking in boys who differ in adiposity but are matched for body mass. Med Sci Sports Exerc 2003;35:669-74.

[68] Hickson RC, Marone RJ. Exercise and inhibition of glucocorticoid-induced muscle atropy. Exercise and Sport Science Reviews 1993;21:135-167. 